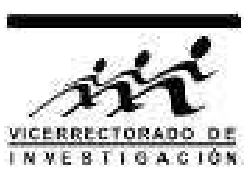

\title{
A study of the $\mathrm{Cu}_{0.95} \mathrm{Al}_{0.05}$ alloy: stress-strain curve and microstructure
}

\author{
Emilio Medrano ${ }^{1}$, Mauro Quiroga ${ }^{1}$ and Felipe A. Reyes*1 \\ ${ }^{1}$ Universidad Nacional Mayor de San Marcos, Facultad de Ciencias Físicas, Laboratorio de Cristales Reales y \\ Aleaciones Metálicas (LABCRAM), Calle Germán Amézaga 375, Lima, Perú
}

Recibido 05 diciembre 2017 - Aceptado 28 enero 2018

\begin{abstract}
After fabricating five metallographic specimens of the $\mathrm{Cu}_{0.95} \mathrm{Al}_{0.05}$ alloy from electrolytic copper and aluminum, these ones were both microstructurally characterized by using a metallographic optical microscope at room temperature and subjected to mechanical traction in order to chart the stress-strain curve. From the characterization, it has been found out that the $\mathrm{Cu}_{0.95} \mathrm{Al}_{0.05}$ microstructure is composed of a single phase, and from the tensile tests, it has been obtained its rupture point, $249.361 \mathrm{MPa}$. The obtained results were explained in the framework of the theory of metals and metal alloys.
\end{abstract}

Keywords: Copper-aluminum alloys, stress-strain curve, heat treatment.

Un estudio de la aleación $\mathrm{Cu}_{0.95} \mathrm{Al}_{0.05}$ : curva esfuerzo-deformación y microstructura A partir de cobre y aluminio electrolíticos, se fabricaron cinco muestras metalográficas de la aleación $\mathrm{Cu}_{0.95} \mathrm{Al}_{0.05}$; posteriormente, a temperatura ambiente, éstas muestras se caracterizaron microestructuralmente via el uso de un microscopio óptico metalográfico. Asimismo, estas muestras fueron sometidas a ensayos de tracción mecánica para obtener datos acerca de la respectiva curva tensión-deformación. Como consecuencia de la caracterización, se encontró que la microestructura $\mathrm{Cu}_{0.95} \mathrm{Al}_{0.05}$ está compuesta de una sola fase; también, de las pruebas de tracción, se ha obtenido su punto de ruptura, 249.361 MPa. Los resultados obtenidos fueron explicados en el marco de la teoría de metales y aleaciones metálicas.

Palabras claves: aleaciones cobre-aluminio, curva tensión-deformación, tratamiento térmico.

\section{Introduction}

Alloys of the copper-aluminum system have different crystal structures and, therefore, various physical properties after a heat treatment. Currently, these properties are exploited in various applications of science, engineering and technology. The copper-aluminum alloy is also referred to as binary aluminum bronze; when small amounts of manganese or nickel are added to this system, it is called (multi-component) aluminum bronze. These bronzes have a strong resistance to corrosion, high strength and good wear resistance. What explains their use in the manufacture of coins, load-bearing masonry fixings, bearing bushes, marine hardware, etc. [1]. Besides, it must be stressed that a copper-aluminum alloy is different from an aluminumcopper alloy, in which copper is the alloying element.

Although the copper-aluminum alloy has been intensively investigated since about the 1920 s, there are notso-ancient works looking for a greater precision of the parameter values for this alloy [2]. Specifically, they are

\footnotetext{
*felipe.reyes@unmsm.edu.pe
}

the works of Ponweiser et al. (2011) and Murray (1985), who experimentally reconstructed the phase diagram of the copper-aluminum alloy [3], 4]. Also, it must be cited the work of Miranda et al. (2016), which, however, is a more specific research about a copper-based alloy having a very low aluminum content $\left(\mathrm{Cu}_{0.975} \mathrm{Al}_{0.025}\right)$ [5].

Motivated by both the works already mentioned and scant information for $\mathrm{Cu}_{0.95} \mathrm{Al}_{0.05}$, we carried out several tensile tests to study its stress-strain curve as well as used optical microscopy to observe its microstructure.

Furthermore, we want to point out that works concerning the $\mathrm{Cu}_{0.95} \mathrm{Al}_{0.05}$ alloy are missing in the available literature.

\section{Theoretical framework}

\subsection{Properties of copper and aluminum}

Some important characteristics of copper are as follows: face-centered cubic (FCC) crystal structure, lattice 
parameter $0.3615 \mathrm{~nm}$, atomic radius $0.128 \mathrm{~nm}$, cubic close packing factor 0.74 as well as density $8.93 \mathrm{~g} / \mathrm{cm}^{3}$; melting temperature $1083^{\circ} \mathrm{C}$ and boiling temperature $2360^{\circ} \mathrm{C}$ [6], [7], [8]. Thus, pure copper is a corrosion resistant material, what allows its use, for example, in the manufacturing of electrical cables, pipes and heat sinks. Besides, copper is a ductile and malleable material having diamagnetic properties.

Concerning aluminum, it also has an FCC crystal structure with a lattice parameter of $0.405 \mathrm{~nm}$; atomic radius $0.143 \mathrm{~nm}$, density $2.72 \mathrm{~g} / \mathrm{cm}^{3}$ and, logically, its cubic close packing factor is 0.74 , too. Besides, its boiling, melting temperatures are $2500^{\circ} \mathrm{C}$ and $658^{\circ} \mathrm{C}$, respectively [9], [10], [11. Nowadays, in the entire world, pure aluminum is a majorly used metal. This is due to its low weight, high strength and good corrosion resistance. Likewise, it is well known that aluminum has a good thermal and electrical conductivity.

\subsection{Properties of the copper-aluminum alloy}

The state diagram of the copper-aluminum alloy predicts that, in a wide range of weight (atomic) percentage of aluminum, different equilibrium phases can be obtained [12]; this can be appreciated in the experimental diagram obtained by Ponweiser et al. in 2011 in an open access article [3]. The reading of the aforementioned phase diagram is very simple below a concentration of $53 \%$ copper; above this weight percentage there is a series of equilibrium phases $\left(\alpha_{2}, \beta, \gamma_{1}, \gamma_{0}, \varepsilon_{1}, \varepsilon_{2}, \zeta_{1}, \eta_{1}, \zeta_{2}, \eta_{2}, \theta, \kappa\right.$ and $\delta)$. Details of these phases can also be found in the same open access article; however, in Fig.1, we have a phase diagram of the aluminum-copper alloy, which shows the corresponding phases of the $\mathrm{Cu}_{0.95} \mathrm{Al}_{0.05}$ alloy. This last phase diagram was reproduced in accordance with the terms of a Creative Commons Attribution-Noncommercial License 3.0 [13].

Another noticeable characteristic, in a phase diagram of copper-aluminum, is the formation of the structures eutectic, eutectoid and peritectic. The first structure is constituted by two solid phases growing simultaneously as a structure interconnected by layers (lamellar structure) [14]. This eutectic phase occurs at $550 \mathrm{~K}$ with a weight percentage $33 \% \mathrm{Cu}$. Compositions below this value are called hypoeutectic and those above, hypereutectic. The second structure reminds the eutectic structure; nevertheless, it occurs when a solid phase is transformed into two different solid phases. The third structure occurs when, upon cooling, a solid-and-liquid phase transforms into another solid phase.

Furthermore, in a usual phase diagram of copperaluminum, it can be noticed that the studied alloy, $\mathrm{Cu}_{0.95} \mathrm{Al}_{0.05}$, is within the range of weight percentages from $90.6 \%$ to $100 \% \mathrm{Cu}$. This range shows the presence of a single phase, a solid solution of alumi- num in copper $\mathrm{Cu}(\mathrm{Al})$. What can be explained by taking into account as follows: copper and aluminum comply with Hume-Rothery's rules to form substitutional solid solutions. These rules indicate that the difference of the atomic diameters must be less than $15 \%$, that they both have the same FCC crystal structure, and that the difference in their electronegativity is 0.3 (which proves to be negligible and, therefore, they cannot form compounds) [9], [10], [15].

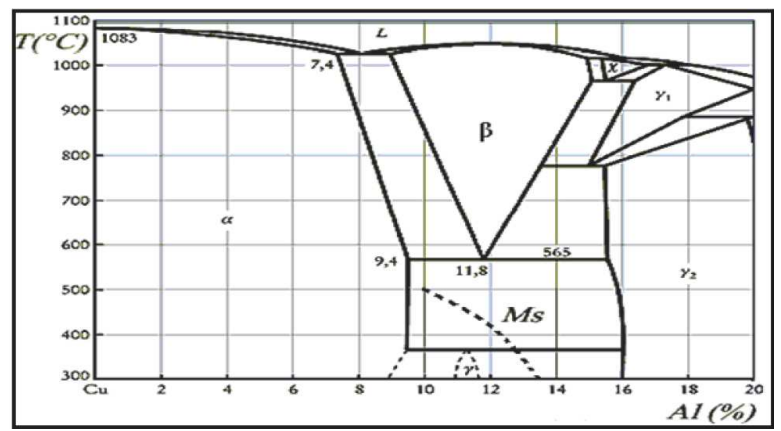

Figure 1: A partial phase diagram of copper-aluminum reproduced from Zeghdane et al. (2010) and Saib (2003) [13]. Alloy eutectoid composition is $11.8 \% \mathrm{Al}$. Also, it is observed temperatures and compositions of the martensitic transformations.

\section{Methodology}

\subsection{Preparation, casting and heat treatment of the sample}

Initially, electrolytic copper and aluminum wires were purchased separately. Then, in the Laboratory of Crystals and Metal Alloys of the National University of San Marcos, by using a crucible and a flamethrower, the wires were cast taking into account the corresponding weight percentage. Afterwards, yet in a liquid state, the alloy was poured into a mold. Subsequently, the already solid sample was allowed to cool to room temperature. Next, the specimens for the corresponding tensile tests were then fabricated.

Also, in order to remove internal tensions accumulate during the lamination, annealing was carried out. Namely, the five metallographic specimens were exposed at $350{ }^{\circ} \mathrm{C}$ for 5 hours inside a furnace; afterwards, these specimens were allowed to cool down in the same furnace.

\subsection{Deburring, polishing and etching}

In the deburring process, burrs were removed by manipulating a deburring machine and three types of abrasive paper $(600,800$ and 1000) [16]. In this process, the use of water was important to clean the burrs taken out by the aforementioned machine.

For polishing, it was used magnesium oxide ( $\mathrm{MgO})$ 
dissolved in distilled water; this solution was soaked in the polishing cloth. Simultaneously, water jets were poured into the specimen. Afterwards, as a consequence, a mirror-like specimen surface was obtained.

The chemical attack was performed before observing the structure of the alloy in the optical metallographic microscope [17]. To carry out the chemical attack, it was used a reagent with the following composition: $4 \mathrm{ml}$ of ferric chloride $\left(\mathrm{FeCl}_{3}\right), 2 \mathrm{ml}$ of hydrochloric acid (aqueous solution of hydrogen chloride, $\mathrm{HCl}$ ), $1 \mathrm{ml}$ of acetic acid $\left(\mathrm{CH}_{3} \mathrm{COOH}\right)$ and 5 drops of liquid bromine $\left(\mathrm{Br}_{2}\right)$.

\subsection{Microscopic Analysis}

An optical metallographic microscope was used to characterize the microstructures present in the samples; specifically, the 1060/62 Euromex microscope was manipulated at magnifications $100 \mathrm{X}$ and $400 \mathrm{X}$, respectively. In general, a microscopic analysis allows determining, for example, the arrangement of the phases as well as grain size and shape after some types of treatments [16]. In the microphotographs, the chemical attack with the aforementioned reagent revealed only one type of microstructure.

\section{Discussion and results}

On the one hand, in figure 2 , for the $\mathrm{Cu}_{0.95} \mathrm{Al}_{0.05}$ alloy, the stress-strain curve was charted. Inside the graphic, the following parameters are noticed: elastic limit $\left(\sigma_{E}=\right.$ $69.267 \mathrm{MPa}$ at $\varepsilon=0.54 \%$ ), yield stress $\left(\sigma_{Y}=71.997\right.$ $\mathrm{MPa}$ at $\varepsilon=0.57 \%)$ and rupture point $\left(\sigma_{R}=249.361\right.$ $\mathrm{MPa}$ at $\varepsilon=14.76 \%$ ); indeed, these three parameters are values of specific stresses [18], [19]. The first one is the maximum stress that can be applied to the specimen before the Hooke's law and its associated Young's modulus are not valid any more. The second one is the stress applied to the specimen before it yielded and, consequently, an irreversible deformation occurred to it. The third one is the stress in which the specimen was fractured. Likewise, between the yield stress and the rupture point, the specimen experienced the phenomenon known as strain hardening [20].

Likewise, in the stress-strain curve in Fig. 2, three regions were observed. The first one comprises up to the $\sigma_{E}$ elastic limit; this region is explained through the mechanism of displacement of atoms from their equilibrium positions. The second region is located between the elastic limit and the yield point; therein appear the first static dislocations in the crystal structure. The third region is the plastic and extends from the $\sigma_{Y}$ yield point to the rupture point $\sigma_{R}$; this region is explained by mechanisms of movement, interaction, multiplication and blocking of dislocations. Namely, inside the crystal structure of the alloy, forests of dislocations are formed, what provokes hardening of the alloy before the rupture. Dislocations are linear defects present in an actual crystal [21], [22].

It must be also pointed out that, in the literature, the rupture point of pure copper is found to be, on average, $220.725 \mathrm{MPa}$ [7]. As a consequence, for $\mathrm{Cu}_{0.95} \mathrm{Al}_{0.05}$, it can be affirmed that the alloying element (aluminum) tended to increase the rupture point of copper.

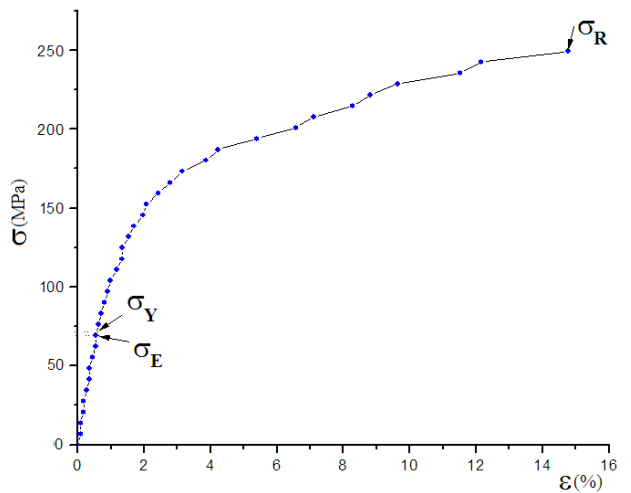

Figure 2: For $\mathrm{Cu}_{0.95} \mathrm{Al}_{0.05}$, stress-strain curve obtained by using a tensile test machine. The elastic limit $\left(\sigma_{E}\right)$, yield stress $\left(\sigma_{Y}\right)$ and rupture point $\left(\sigma_{R}\right)$ are observed.

On the other hand, in Fig. 3, two microphotographs of the metallographic specimens are observed. Fig. 3a shows a 100X magnification and Fig. 3b, a 400X magnification. This last resolution is the most important, because the light areas allow us to see the formation of a single phase (substitutional solid solution). Likewise, the dark areas represent the high relief that occurs as a result of the pitting corrosion of the sample, which is due to the chemical attack. Also, it is noticed that the single phase is uniformly distributed. This uniformity is in accordance with what is observed in a usual Cu-Al phase diagram. In other words, there is uniformity as it is a single solid solution of aluminum in copper.

(a)

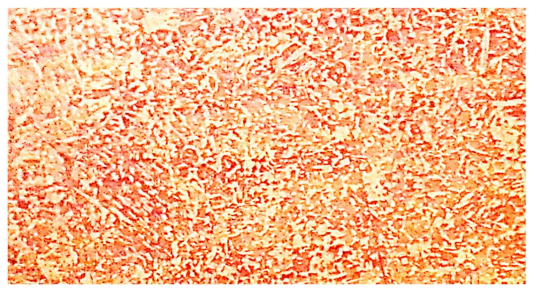

(b)

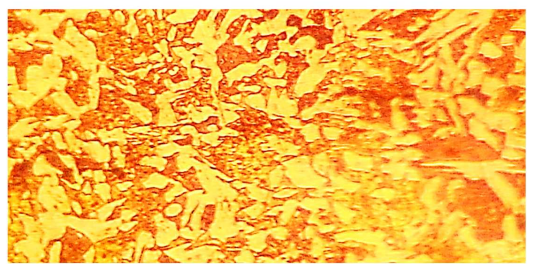

Figure 3: $\mathrm{Cu}_{0.95} \mathrm{Al}_{0.05}$ microphotographs obtained through an optical metallographic microscope. The upper and lower panels show a magnification of $100 \mathrm{X}$ and $400 \mathrm{X}$, respectively.. 


\section{Conclusions}

On the one hand, by using optical metallographic microscopy, it has been found that, microstructurally, the investigated alloy has a phase distribution formed by a substitutional solid solution. These phases are uniformly distributed throughout the $\mathrm{Cu}_{0.95} \mathrm{Al}_{0.05}$ sample.

On the other hand, by tensile test experiments, it has been obtained the value of the rupture point of the alloy, 249.361 MPa, which is greater than that of pure copper, $220.725 \mathrm{MPa}$.

\section{Acknowledgments}

Concerning the improvement of this paper, we recognize the suggestions and comments from J. Moreno and J.G. Miranda Ramos, colleagues at the National University of San Marcos (UNMSM).

\section{References}

[1] Copper Development Association. Aluminium Bronze Alloys - Corrosion Resistance Guide. Publication No. 80, 1-26. Available from www.cda.org.uk (1981).

[2] R.E. Sanders; The Journal of the Minerals. 53(2):2125 (2001).

[3] N. Ponweiser, Ch.L. Lengauer and K.W. Richter; Intermetallics 19(11):1737-1746 (2011).

[4] J.L. Murray; Int. Met. Rev. 30(1):211-234 (1985).

[5] J.G. Miranda Ramos, E. Medrano Atencio, M. Quiroga Agurto and F.A. Reyes Navarro; J. Met. Mater. Miner. 26(2):31-36 (2016).

[6] B.A. Kuzmin and A.I. Samojotski; Metallurgy, metallography and special-purpose materials [Metalurgia, metalografía y materiales de construcción]. Mir Publishers, Moscow (Russia) (1986).

[7] Y.M. Lajtin; The metallography and heat treatment of metals [Metalografía y tratamiento térmico de los metales]. Mir Publishers, Moscow (Russia) (1977).

[8] J. Herenguel; Special metallurgy, Vol. 2: Copper and its alloys [Metalurgia especial, Tomo II: cobre y sus aleaciones]. Urmo Publishers, Spain (1976).

[9] R.E. Reed-Hill; Physical Metallurgy Principles [Principios de metalurgia física]. Cecsa Publishers, Mexico (Mexico) (1986).
[10] W.F. Smith and J. Hashemi; Foundations of Materials Science and Engineering [Fundamentos de la ciencia e ingeniería de materiales]. McGraw-Hill Publishing Company, Mexico (Mexico) (2004).

[11] J.G. Miranda Ramos; Resistividad eléctrica de la aleación cobre aluminio en función de la deformación plástica [Electrical resistivity of copper-aluminum alloy as a function of plastic deformation], Licentiate thesis, Lima (Peru), Universidad Nacional Mayor de San Marcos (2006).

[12] H. Baker (Editor); ASM International Handbook, Vol. 3 - Alloy phase diagrams (1992).

[13] S. Zeghdane, K. Necib and A. Britah; Structural Characterization of $\mathrm{Cu}-13.58 \% \mathrm{Al}-3.94 \% \mathrm{Ni}$ (wt. \%) shape memory alloy elaborated by fusion. EPJ Web of Conferences; 6, 29001 (2010). DOI:10.1051/epjconf/20100629001.

[14] H. Föll; Iron, steel and swords. Available from http://www.tf.unikiel.de/matwis/amat/iss/index.html

[15] P.V. Pávlov and A.F. Jojlov; Física del estado sólido [Solid state physics] Mir Publishers, Moscow (Russia) (1984).

[16] Dr. E.J. Dubox; Prácticas de metalografía [Practices of metallography]. Marymar Publishers, Buenos Aires (Argentina). (1974).

[17] G.F. Vander Voort; ASM International Handbook; Vol. 9 (2004).

[18] ASM International. Atlas of stress-strain curves. 2nd edition, 816 pp (2002).

[19] S. Timoshenko; Strength of materials. Part I. Elementary theory and problems. D Van Nostrand Company, 2nd edition, 18th printing, New York (USA) (1948).

[20] G.E. Dieter; Mechanical metallurgy. Metallurgy and metallurgical engineering series, McGraw-Hill, USA (1961).

[21] J. Friedel, R. Smoluchowski and N. Kurti; Dislocations. International series of monographs on solid state physics, Elsevier Ltd. (1964).

[22] D. Hull and D.J. Bacon; Introduction to dislocations, 4th edition, Butterworth-Heinemann, Oxford (UK) (2001). 